\title{
YVES BONNEFOY, Correspondance I
}

\section{Fabio Scotto}

\section{CpenEdition \\ Journals}

\section{Edizione digitale}

URL: http://journals.openedition.org/studifrancesi/16732

DOI: 10.4000/studifrancesi. 16732

ISSN: 2421-5856

\section{Editore}

Rosenberg \& Sellier

\section{Edizione cartacea}

Data di pubblicazione: 1 juillet 2019

Paginazione: 193-194

ISSN: 0039-2944

\section{Notizia bibliografica digitale}

Fabio Scotto, «Yves bonnefor, Correspondance I», Studi Francesi [Online], 187 (LXIII | I) | 2019, online dal 01 juillet 2019, consultato il 25 janvier 2021. URL: http://journals.openedition.org/studifrancesi/16732 ; DOI: https://doi.org/10.4000/studifrancesi. 16732

Questo documento è stato generato automaticamente il 25 janvier 2021.

\section{(c) (†)}

Studi Francesi è distribuita con Licenza Creative Commons Attribuzione - Non commerciale - Non opere derivate 4.0 Internazionale. 


\title{
YVES BONNEFOY, Correspondance I
}

\author{
Fabio Scotto
}

\section{NOTIZIA}

YVES BONNEFOY, Correspondance I, édition établie, introduite et annotée par Odile Bombarde et Patrick Labarthe, Paris, Les Belles Lettres, 2018, 1156 pp.

1 Costituisce indubbiamente un grande evento editoriale la recente pubblicazione del primo volume (numerosi altri ne sono previsti nel piano editoriale dell'opera) della Correspondance di Yves Bonnefoy, che si deve alle amorevoli cure di due dei suoi più fedeli filologi e critici.

2 So per esperienza diretta e personale dalle mie conversazioni con il poeta come egli fosse assai cauto riguardo alla possibilità di pubblicare la sua corrispondenza (anzi a me disse anni fa che riteneva che non l'avrebbe mai pubblicata, ritenendola un aspetto della sua vita del tutto privato e personale). Se è stato convinto da alcuni suoi amici e collaboratori a cambiare idea in merito al termine della sua esistenza, con vivo beneficio, diciamolo, dei suoi lettori e studiosi, ciò è dovuto alle motivazioni che opportunamente adducono i curatori nella loro «Introduction» (pp. vII-XXII), i quali, nel leggere le commoventi e intense lettere che Bonnefoy indirizzò nel 1969 all'amico Boris de Schloezer poco prima della sua morte, furono «frappés par la profonde résonance entre ces lettres, leur circonstance, et la nature et la fonction même de la poésie comme Bonnefoy les a comprises».

3 Va detto che non si tratta affatto di un'edizione esaustiva dell'intera corrispondenza di Bonnefoy, ne sono infatti escluse, per esplicita volontà dell'Autore, le lettere alle due mogli e ai membri della famiglia; siamo semmai di fronte a una selezione di lettere relative a una corrispondenza prettamente letteraria «avec des poètes, des artistes, des écrivains ou des penseurs qui ont pour point commun d'avoir donné une place essentielle, dans leur vie, à la création artistique ou à la connaissance» (p. vII). Scettico riguardo al pessimo uso che spesso fanno i biografi della corrispondenza degli autori, Bonnefoy aveva inteso cautamente indicare delle «lignes de force» che costituiscono la 
materia di questo volume, ovvero quelle relative alle due epoche intellettualmente e poeticamente fondative della sua opera, vale a dire in primis la stagione surrealista, da Breton a Dotremont, Henein, Mandiargues, Bellmer, Ubac e altri, alla stagione della rivista «L'Éphémère» (1967-1972), edita da Maeght, pubblicazione che riunì personalità quali du Bouchet, Dupin, Picon, des Forêts, Celan, Giacometti.

4 L'itinerario è indubbiamente appassionante e dà conto di un'avventura intellettuale e poetica volta a quella che Bonnefoy chiama «une recherche en commun» che abbraccia tutti i campi del sapere e mostra, oltre all'interesse culturale, un profondo investimento umano nel rapporto con l'altro e con la sua vita quotidiana fatta anche di affetti, inquietudini, problemi materiali e professionali.

5 L'ordine seguito, che è cronologico e corredato di preziose note introduttive alle varie sezioni, consente anche di ben cogliere l'evoluzione degli eventi che danno vita a un romanzo ideale, quello di un'avventura umana che ha saputo coagulare energie vitali per lo sviluppo della cultura nel corso di un settantennio nel quale scriversi lettere era scrivere, muovere idee, mantenere vivi entusiasmi, crescere insieme, a volte litigare, altre volte scusarsi, comunque sempre parlarsi, crescere, vivere con gli altri, cosa che chi ha avuto il privilegio di conoscere e corrispondere con Bonnefoy ben sa quanto per lui fosse essenziale e irrinunciabile.

6 Si segnala altresì l'uscita del saggio di Yvon INIZAN Ce que le poète dit au philosophe. Yves Bonnefoy, la pensée du poème (Rennes, Éditions Apogée, 2018, 77 pp.), che affronta in un saggio quadripartito, con l'intelligenza che si riconosce al suo autore anche per sue prove specifiche precedenti, la problematica del rapporto fra poesia e filosofia che fu sempre cara all'autore di Anti-Platon. 